\title{
STABILITY OF RUBBLE MOUND BREAKWATERS IN SHALLOW WATER AND SURF ZONE : AN EXPERIMENTAL STUDY
}

\author{
Guirec PREVOT ${ }^{1}$, Olivier BOUCHER ${ }^{1}$, Maryline LUCK $^{2}$ and Michel BENOIT ${ }^{2}$ \\ Rubble-mound breakwaters are often pre-designed with empirical formulae allowing the estimation of armour stone size \\ or weight, taking into account the wave conditions (mainly a characteristic wave height and a characteristic period), the \\ type and density of stone or block used, the slope of the mound, the acceptable level of damage, etc. In deep water \\ conditions, the existing formulas are rather well established (e.g. Hudson and Van der Meer formulas among others). They \\ use as input data wave parameters that are well defined (e.g. the significant wave height $\mathrm{H}_{1 / 3}$ or sometimes the height $\mathrm{H}_{1 / 10}$ ) \\ and easily accessible, from in situ measurements or from numerical wave models.
}

\begin{abstract}
In shallow water however, and in particular in breaking wave conditions (where most of the small breakwaters are built), a number of physical processes (refraction, shoaling and breaking) significantly modify the incoming waves. They also lead to changes in the wave height distribution (which can no longer be regarded as being of Rayleigh-type) and in the shape of the wave spectrum. This, combined with the fact that most of the models used nowadays for nearshore wave propagation are spectral wave models (e.g. SWAN, TOMAWAC, etc.) and thus provide spectral parameters as output (typically the spectral significant wave height $\mathrm{H}_{\mathrm{m} 0}$ and the peak period $\mathrm{T}_{\mathrm{p}}$ or the mean energetic period $\mathrm{T}_{\mathrm{m}-1,0}$ ) has raised the question of which characteristic wave parameter should be used in stability formulas for rubble-mound breakwaters in shallow water. This has led to the consideration of more representative wave parameters such as $\mathrm{H}_{2 \%}$ or $\mathrm{T}_{\mathrm{m}-1,0}$ which are sometimes less accessible from existing wave database or numerical modelling studies.
\end{abstract}

The objective of the present study is to review and compare several available methods to calculate armour stone weight in shallow waters, and to provide some insight into the applicability and limitations of these methods based on a series of wave flume experiments.

Keywords: rubble-mound breakwater; shallow water; damages.

\section{INTRODUCTION}

Presently, the design of rubble mound breakwaters is realized through pre-design formulas. These formulas have been developed empirically through experimental tests due to the fact that the hydrodynamic forces on breakwaters are not well understood. They are known as pre-design formulas since they allow the designer to have initial sizing estimates for the breakwater. Pre-design is generally verified afterwards using a model which then can be used to refine design dimensions. The first formula was developed by Hudson in the 1950s. Since then, many formulas have appeared. But, the former still remains the most used. It is certainly easy to implement, but, it is only valid for the propagation of an incident non-breaking wave on a flat seabed. In the surf zone, the wave spectrum is modified and the hydrodynamic effects on the armour stone are complex. This is the reason for which many authors are interested in the stability of breakwaters in shallow water zones.

This study is part of a research program (Programme Biparti EDF/Ministère) motivated by the numerous existing rubble mound breakwaters in shallow water as well as those that are to be constructed. The objective of this study is to revisit and compare the methods employed to pre-design armour stone in shallow water conditions as well as to confirm or identify limitations in the applicability of these methods based on many series of tests conducted in a wave tank.

\section{BIBLIOGRAPHY}

Waves are oscillations concerned only with the upper part of the fluid. They can be assumed to propagate without deformation at sufficient depths. When approaching shores or structures their propagation is modified due to the effects of bathymetry. Wave amplitudes increase, the waves rise : this is the phenomenon known as shoaling. Next follows breaking, the phenomenon where the wave is destroyed. The latter phenomenon is characterized by a large degree of turbulence and high energy dissipation. These are the conditions investigated by this study.

\section{Shallow Water}

\footnotetext{
1 CETMEF, 2 Boulevard Gambetta, Compiègne, 60200, France

2 EDF, LNHE, 6 Quai Watier, Chatou, 78400, France
} 
Many authors have proposed pre-design formulas for armour stone taking into account a limited water depth. Some authors (for example Van der Meer) define shallow water by directly comparing the water depth to the significant wave height at the toe of the structure:

- when $3 \mathrm{H}_{\mathrm{s} \text { toe }}>\mathrm{D}_{\mathrm{p}}$, the structure is in shallow water;

- when $3 \mathrm{H}_{\mathrm{s}}$ toe $<\mathrm{D}_{\mathrm{p}}$, the structure is in deep water.

More recently, Van Gent has established criteria related more to propagating wave energy dissipation by studying the ratio of the significant wave height at the structure to that observed offshore :

- when $\mathrm{H}_{\mathrm{s} \text { toe }} / \mathrm{H}_{\mathrm{s} \text { offshore }}>0.9$, the structure is in deep water ;

- when $0.7>\mathrm{H}_{\mathrm{s} \text { toe }} / \mathrm{H}_{\mathrm{s} \text { offshore }}>0.9$, the conditions are said to be shallow water conditions ;

- when $\mathrm{H}_{\mathrm{s} \text { toe }} / \mathrm{H}_{\text {s offshore }}<0.7$, the conditions are said to be very shallow water conditions.

Essentially, the zone where shoaling and breaking takes place is the shallow water zone. The experiments focus on these particular conditions.

\section{Pre-design Formulas}

\section{Stability Number}

This number is very important and widely used, it is the design parameter. It provides a relationship between the characteristics of the structure and those of the wave.

$$
N_{s}=\frac{H_{\text {s ourrage }}}{\Delta D_{n 50}}
$$

where Dn50 is the median nominal diameter (dimension of the equivalent median cube) and where $\Delta$ is the relative buoyant density of the stone.

$$
\Delta=\frac{\rho_{r}}{\rho_{\omega}}-1
$$

\section{The EDF Method or Feuillet Method}

This method is based on the Hudson formula which is still the most widely used. The EDF method is one of the first to have taken into account phenomena that can occur in shallow water.

The Hudson formula can be written in the following form:

$$
N_{s}=\left(K_{D} \cot (\alpha)\right)^{(1 / 3)}
$$

where $K_{D}$ is a stability coefficient which depends on block properties, their orientations, the number of layers, admissible retained damage and embankment angle $\alpha$.

This formula is applicable to natural or artificial rubble mound breakwaters in deep water and for nonbreaking waves propagating on a flat seabed. This formula does not take into account the stage or the duration of the storm.

The EDF method permits application of the Hudson formula to conditions which are both more complex and more realistic. It uses a table lookup for different seabed slopes in front of the structure $(1 \%, 5 \%, 10 \%)$. As a function of wave steepness (gamma, $\gamma$ ), the water depth at the toe of the structure $\left(D_{p}\right)$ and the offshore wave height $\left(\mathrm{H}_{1 / 10 \text { offshore }}\right)$, the tables provide a nominal value $\mathrm{Hd}$, called the design wave height. This approach takes into account the influence of shoaling and wave capping as illustrated by the table below. 


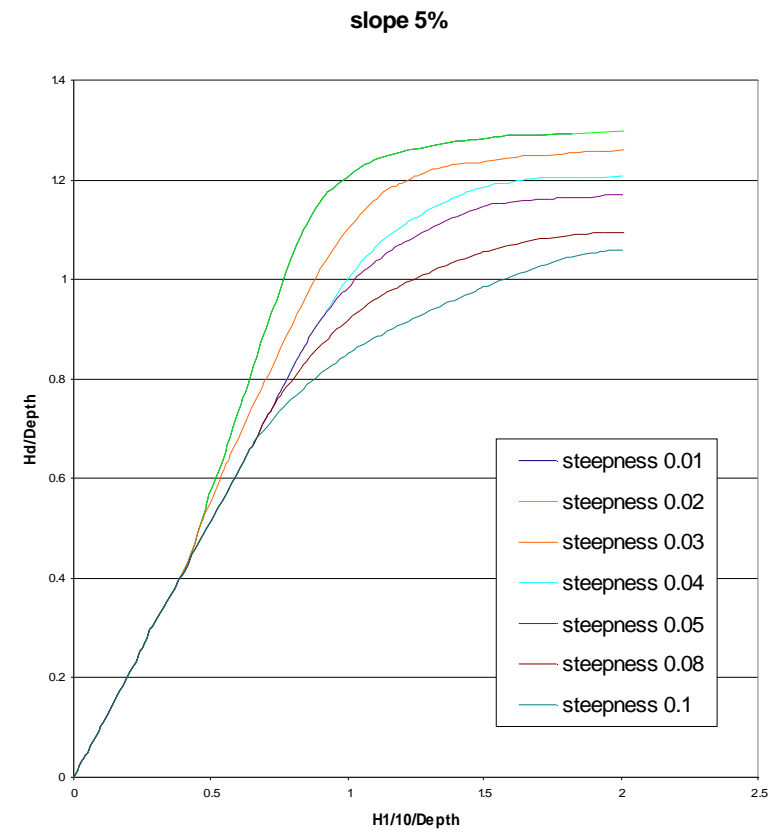

Figure 1 : Table for the Method given by Feuillet et al. for a slope of $5 \%$

\section{The Van der Meer Formulas Modified by Van Gent for Shallow Water}

In 1988, Van der Meer proposed two equations for deep water. These equations were modified by Van Gent $e t$ al. in 2004 in order to adapt them to shallow water. In shallow water, because of the physical phenomena previously described, the wave height distribution no longer follows the Rayleigh distribution (as is the case for deep water). The spectral peak becomes more fine and antisymetric. According to studies by Van Gent and his colleagues, $\mathrm{H}_{2 \%}$ and $\mathrm{T}_{\mathrm{m}-1,0}$ would be the significant hydraulic parameters to size the armour stone in shallow water.

Remark : In deep water, Van der Meer (1988) proposes the use of $H_{s}$ and $T_{m}$.

For pre-design, two types of breaking waves are distinguished: plunging breakers and surging breakers. Breaking waves are quantified by the Iribarren number, or surf similarity parameter.

$$
\xi_{c r}=\left[\frac{c_{p l}}{c_{s}} P^{0.31} \sqrt{\tan \alpha}\right]^{\frac{1}{P+0.5}}
$$

In shallow water, the period used in the Iribarren number is $T_{\mathrm{m}-1,0 .}$. The parameter is therefore denoted by $x_{s-1,0}$. The values obtained are compared to the critical Iribarren number.

$$
\xi=\tan \alpha / \sqrt{ }\left(2 \pi H_{1 / 3} /\left(\mathrm{g} T^{2}\right)\right)
$$

The values of the coefficients $c_{\mathrm{pl}}$ and $\mathrm{c}_{\mathrm{s}}$ are 8,4 and 1,3, respectively (6,2 and 1 in shallow water).

Thus, for a storm with a duration of $\mathrm{N}$ waves assumed to be plunging breakers $\left(\xi_{s-1,0}<\xi_{c r}\right)$, Van Gent proposes :

$$
N_{s}=\frac{H_{s}}{\Delta D_{n 50}}=c_{p l} P^{0.18}\left(\frac{S_{d}}{\sqrt{N}}\right)^{0.2}\left(\frac{H_{s}}{H_{2 \%}}\right) \xi_{s-1,0}{ }^{-0.5}
$$

and for surging breakers $\left(\xi_{s-1,0 \geq} \xi_{c r}\right)$ :

$$
N_{s}=\frac{H_{s}}{\Delta D_{n 50}}=c_{s} P^{-0.13}\left(\frac{S_{d}}{\sqrt{N}}\right)^{0.2}\left(\frac{H_{s}}{H_{2 \%}}\right) \sqrt{\cot \alpha} \xi_{s-1,0} P
$$

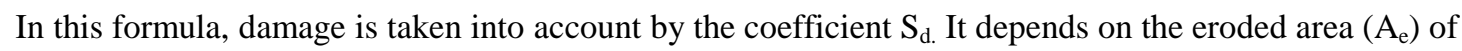
the breakwater profile. 


$$
S_{d}=\frac{A_{e}}{\left(D_{\mathrm{n} 50^{2}}\right)}
$$

The permeability $(\mathrm{P})$ as defined by Van der Meer appears in the equation. In the case of our reduced model, consisting of a double layer of rock and a filter layer, the permeability is set to 0,4 .

\section{Van Gent Method}

Van Gent proposed, in 2004, a new equation that no longer takes into account the period. Permeability is however still taken into account though instead by the ratio of the core and armour stone median nominal diameters.

$$
N_{s}=\frac{H_{s}}{\Delta D_{n 50}}=1,75 \sqrt{\cot \alpha}\left(\frac{S_{d}}{\sqrt{N}}\right)^{0.2}\left(1+\frac{D_{n 50 \text { noxanu }}}{D_{n 50}}\right)^{(2 / 3)}
$$

\section{Accounting for Damage}

The concept of damage is extremely complex because there are several definitions. The referenced formulas each use a different approach to quantify damage. For the remainder of the study, a single definition is accepted, that defined by the Shore Protection Manual (CERC, 1984) [11] where damage is characterised by the «normalised eroded volume in the active region, since [...] the ridge until $1 H_{s}$ below the water level at rest. » Damage is denoted by $\mathrm{D}$, and is given by :

$$
D=\frac{\text { displaced units }}{\text { units in the active area }}(10)
$$

Remark : this definition was adopted to account for damage in our study (cf. 2.4)

In order to make comparisons during the experimental phase, it is necessary to establish relationships between these definitions.

\begin{tabular}{|c|c|c|c|c|}
\hline $\mathrm{D}(\%)$ & $0-5$ & $5-10$ & $10-15$ & $15-20$ \\
\hline $\mathrm{Sd}(-)$ & 2 & 6 & 10 & 14 \\
\hline
\end{tabular}

\begin{tabular}{|c|c|c|c|c|}
\hline $\mathrm{D}(\%)$ & $0-1$ & $1-5$ & $5-10$ & $10-20$ \\
\hline $\mathrm{Kd}(-)$ & 3.2 & 5.1 & 7.2 & 9.5 \\
\hline
\end{tabular}

Figure 2 : Relationship Between Different Definitions of Damage (Rock Manual et Feuillet et al. (1987))

\section{Pre-design Method Conclusions}

Three pre-designing methods exist which are valid in shallow water. Furthermore, currently the formulas adapted for shallow water are used very little because of their more recent development and their complexity. Structures are still very often pre-designed with the help of the Hudson formula because of its ease of utilisation.

It is therefore of interest to compare these formulas, which are valid for shallow water, through experimental tests in order to evaluate their validity.

\section{DESCRIPTION OF EXPERIMENTAL SETUP}

The model is installed in Canal 12 of LNHE at Chatou. This particular wave tank is $45 \mathrm{~m}$ long and has a cross-section of $0,6 \times 0,8 \mathrm{~m}$. (lxh)

In order to meet the needs of the study, the model must: 
- meet the shallow water conditions : a slope of 3\% was constructed over $9 \mathrm{~m}$ in front of the model which allows breaking waves to occur before the structure.

- achieve a damage level on the order of 15 to $20 \%$, in the range of possible flow conditions that can be generated in the channel

The scale used for the model is $1 / 42$, according to Froude similitude. The experimental breakwater is $50 \mathrm{~cm}$ high with a slope of $3 / 2$ and a base width of $1.70 \mathrm{~m}$

The materials used for the breakwater construction were carefully calibrated and filter criteria was strictly respected. The armour stone materials are modelled by $35-90 \mathrm{~mm}$ alabaster blocks whose median mass $\left(\mathrm{M}_{50}\right)$ is $66.7 \mathrm{~g}$ and whose density is 2.8 . The filter layer is constructed with $15-20 \mathrm{~mm}$ alabaster blocks whose median mass $\left(\mathrm{M}_{50}\right)$ is $5.4 \mathrm{~g}$. The core consists of coarse sand whose finer grains were removed.
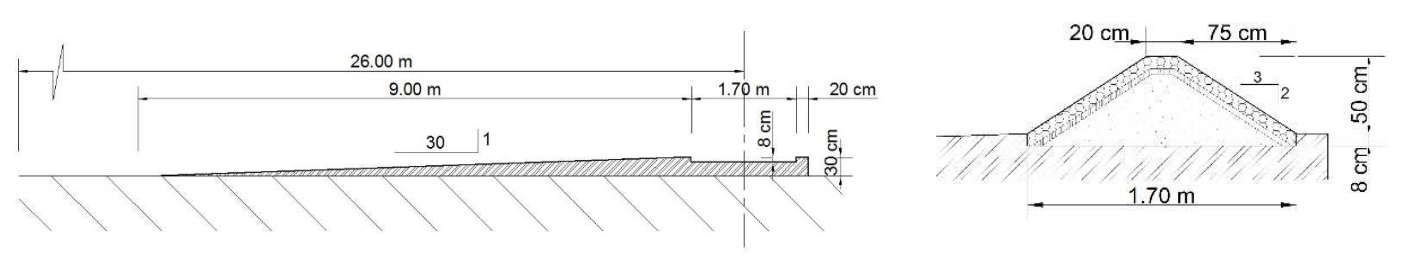

Figure 3 : Characteristics of the Slope in the Channel and of the Reduced Breakwater Model

In order to have a good statistical wave height distribution, a sequence of 2000 waves was generated for each test (this represents tests with a duration of between $45 \mathrm{mn}$ and $1 \mathrm{~h} 30$ as a function of the chosen periods, JONSWAP spectrum). The wave amplitude that can be generated depends on the water level in the channel and the period.

Water level measurements are obtained using 7 sensors. The 3 sensors which are placed 7 to $8 \mathrm{~m}$ before the slope measure the incident/reflected wave. The $4^{\text {th }}$ sensor placed at the beginning of the rising seabed measures the wave considered to be offshore. The 3 remaining sensors are placed along the seabed slope up to the base of the structure. After analysing the signals obtained from these sensors, one can determine the spectral parameters as well as the statistics of the wave produced.

Damage is measured in terms of cumulative damage, assuming that the damage occurring at a water level of wave height $\mathrm{H}$ would occur at a water level of $\mathrm{H}+\Delta \mathrm{H}$. The value is obtained visually.

The protocol is as follows :

- water level adjusted in the channel (initially to the lowest level)

- wave period selection (smallest value)

- wave generation beginning with a low amplitude

- at the end of the first test, the amplitude of the wave is incremented for the following test (approximately in $4 \mathrm{~cm}$ increments)

- when damage reaches approximately $15 \%$, a large area of the armour stone is destroyed, or the lower armour stone area is attacked, testing is stopped. The armour stone is entirely reconstructed and the sequence is completed

- a new sequence is carried out for a more elevated water level or a greater period.

Each sequence is repeated 5 times. This repetition can be extremely important. Damage is a very sensitive parameter. Measurements accounting for damage can vary on the order of $30 \%$. In fact, damage depends heavily on how the breakwater was rebuilt.

Damage is measured at the end of the test. Blocks are considered displaced if :

- they are ejected outside the active region $\left(\mathrm{D}_{\mathrm{p}}-\mathrm{H}_{1 / 3}, \mathrm{D}_{\mathrm{p}}+2.5 \mathrm{H}_{1 / 3}\right)$

- they are displaced within the active region such that they overlap with the second armour stone 
layer

Blocks are not individually differentiated. If a block is moved, but only occupies a gap left by another, no displacement is recognized - considering that the block still maintains its protective role.

For example, in the image below a pile of blocks ejected from the active region is found at the base of the breakwater. Their displacements contribute to the calculation of damage.

The block labeled $\mathrm{X}$ is also considered displaced. It has not been ejected from the active region but it is overlapping, in other words, it is in a « $3^{\text {rd }}$ layer».

On the other hand, certain blocks which have moved - and that we easily identify thanks to their unique colour with respect to neighbouring blocks - do not contribute to the damage calculation. For example, this is the case for red block B. This particular block fell down within the armour stone but it occupies the position vacated by block A which exited the active region. It is therefore the same as if B had left the active region and A had not moved. The protection function is found in the same manner.
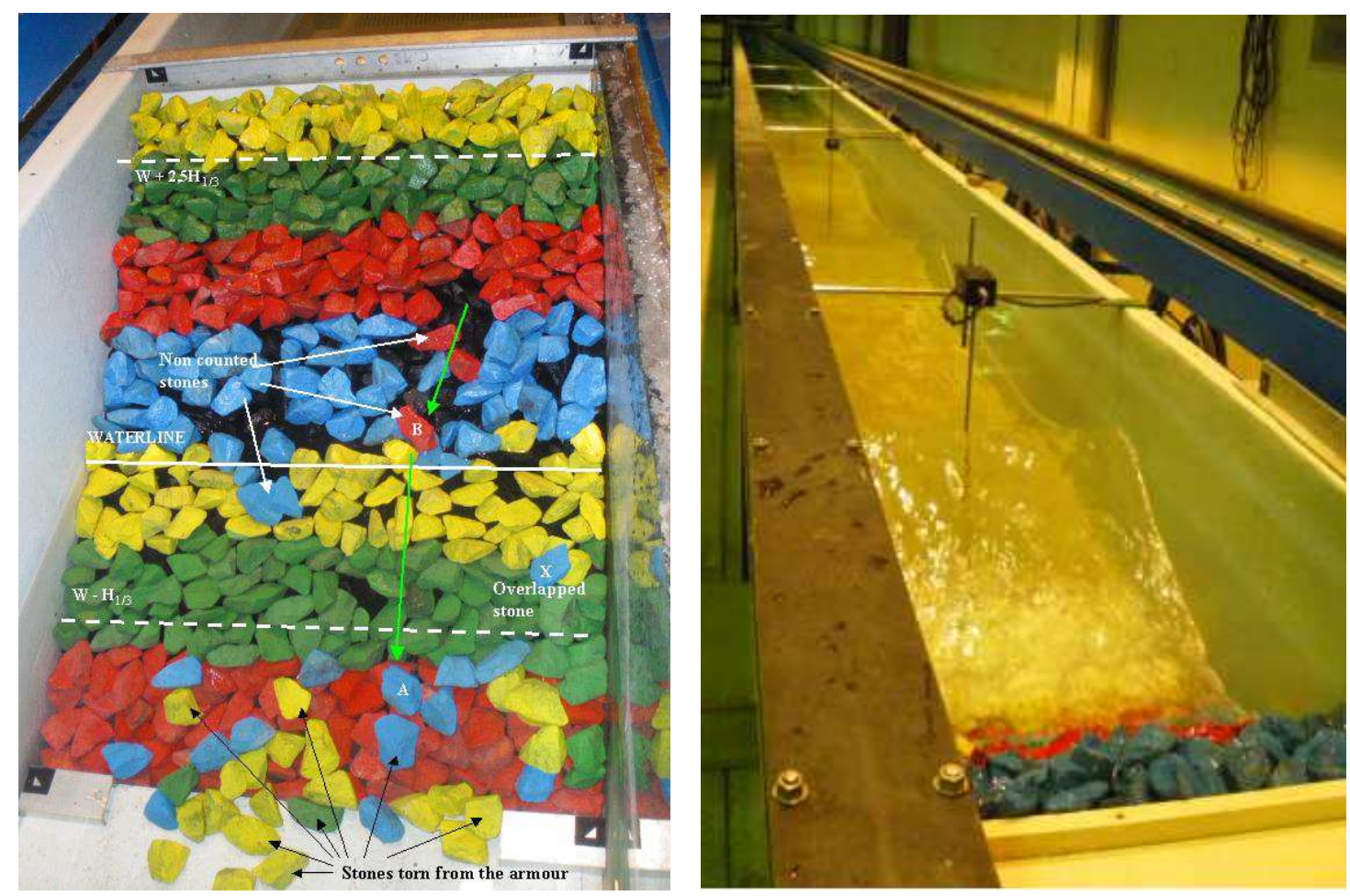

Figure 4 : Photograph of the Damaged Breakwater with Explanation of the Damage Calculation (left) and the Test Channel (right)

\section{RESULTS}

\section{Validation of Shallow Water Conditions}

Shallow water conditions were considered. The two above mentioned criterion $\left(0.7>H_{s}\right.$ toe $/ H_{s}$ offshore $>$ 0.9 and $3 H_{s}$ toe $>D_{p}$ ) quantify these conditions. It is observed, in the figure below, that the first criterion is not necessarily respected while the second corresponds to the objectives sought. However, in shallow regions, as mentioned above, shoaling causes the waves to swell. These waves see their amplitude approach or exceed their height far from shore (the ratio $H_{s}$ toe $/ H_{s}$ offshore can therefore be in the neighbourhood of unity). The open sea was considered in all experiments to be at the start of the slope. We can therefore consider in viewing these images, that the shallow water conditions are linked : according to the conditions, we observe, respectively, wave heights limited by breaking and wave heights amplified by shoaling. 
Remark: The first criteria $\left(0.7>H_{s}\right.$ toe $/ H_{s}$ offshore $\left.>0.9\right)$ seems to define the shallow zone as the zone where the waves are only clipped by breaking.

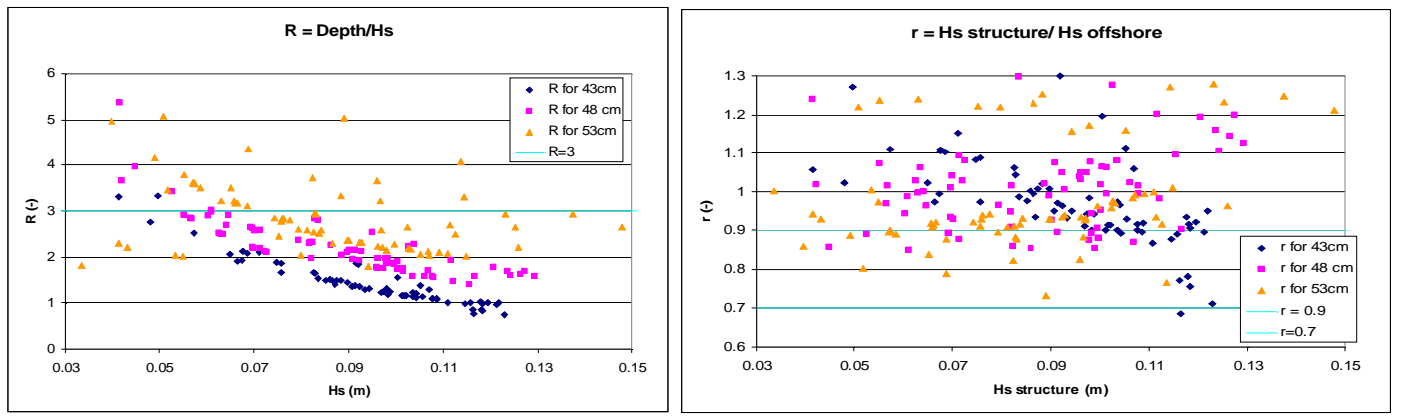

Figure 5 : Shallow Water Criteria : $0.7>\mathrm{Hs}$ toe/Hs au large $>0.9$ (left) and $3 \mathrm{Hs}$ toe $>\mathrm{Dp}$ (right)

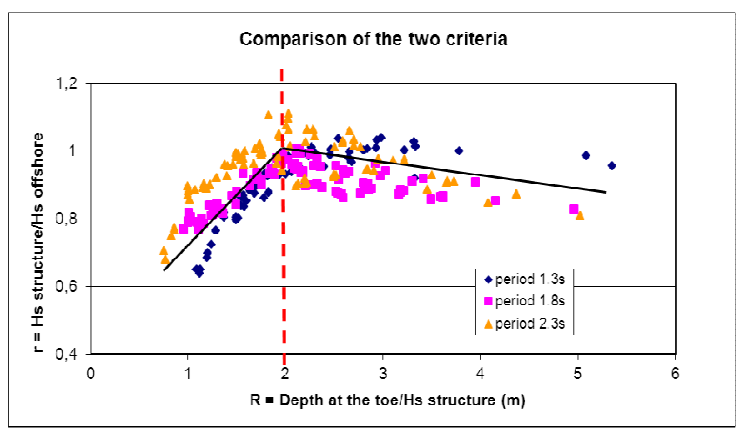

Figure 6 : Comparison of the two criteria

Two behaviours can be shown. Two branches appear to materialize with an inflection point around $\mathrm{R}=2$. From the inflection point $(\mathrm{R}=2)$ to $\mathrm{R}=0, \mathrm{r}$ can decrease from 1 to 0.7 that means a high rate of breaking.

\section{Results by Levels and Periods}

All of the tests (approx. 250) are represented in the following table (figure 7) and are classified by water level in the channel and period. During these tests, observations of the wave break type produced on the slope were made. The point colour and style indicates the observed wave break type.

By analysing the type of wave break produced (before the structure, on the slope), one concludes that with a shorter period and a lower level, spilling breaking occurs. For increasing levels and increasing periods a progression towards plunging and surging breakers is seen.

The theoretical results are determined with the help of the structure incident wave value. The Van der Meer formula adapted for shallow water corresponds relatively well with the test results.

The Feuillet method provides good results for more significant levels and periods. The Van Gent method appears to be more relevant for low water levels and short periods. The following schematic summarises the observations and results.

The Van Gent formula (2004) is not the most significant in the analysis of the experimental test cases. The theoretical formula from Van Gent (2004) approaches the test results for cases with lower water levels and with shorter periods. This formula is valid for very shallow conditions $H_{s}$ toe $/ H_{s}$ au large $<0.7$. Such conditions were not obtained. 


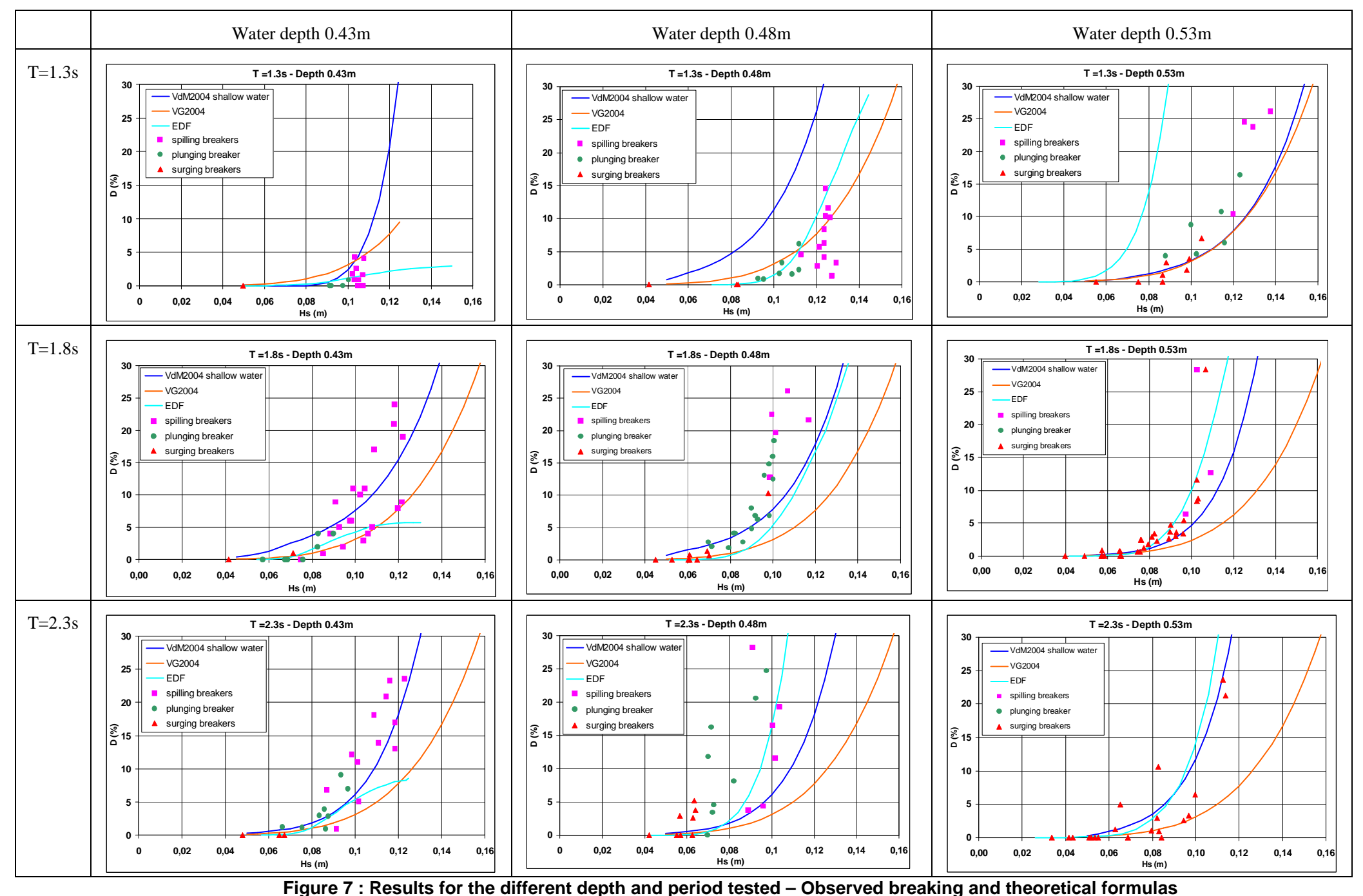




\section{Results for All Conditions}

The preceding paragraph shows that the Van der Meer formula adapted for deep water presents a good correlation with the experimental test results. It is therefore interesting to compare this formula to test sets. (Remark : the calculation of the surf similarity parameter yields plunging breakers on the structure for all of the tests)

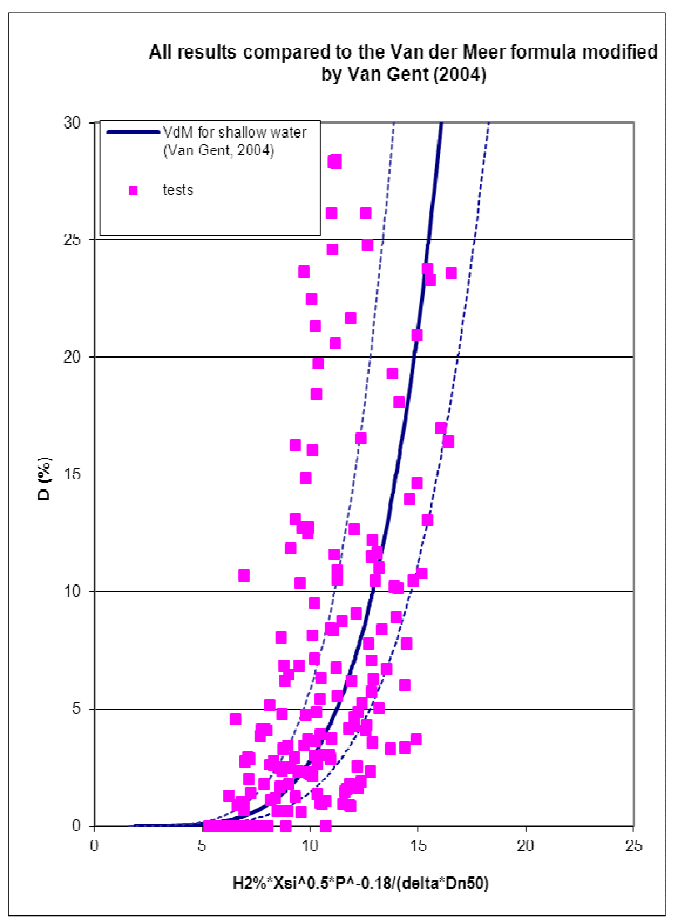

Figure 7 : Test Sets Compared to the Van der Meer Formula Modified by Van Gent (2004) for Shallow Water

Looking at the image in figure 8 , two branches seem to materialize. The hypothesis of two behaviours depending on shallow water or deep water conditions is clear.

The criteria $3 H_{s}$ toe $>D_{p}$, is used in order to try to distinguish these two behaviours. Tests are sorted according to the criteria and represented on the images corresponding to the Van der Meer formula (1988) utilised for deep water and to the Van der Meer modified by Van Gent (2004) for shallow water (figure 9). 

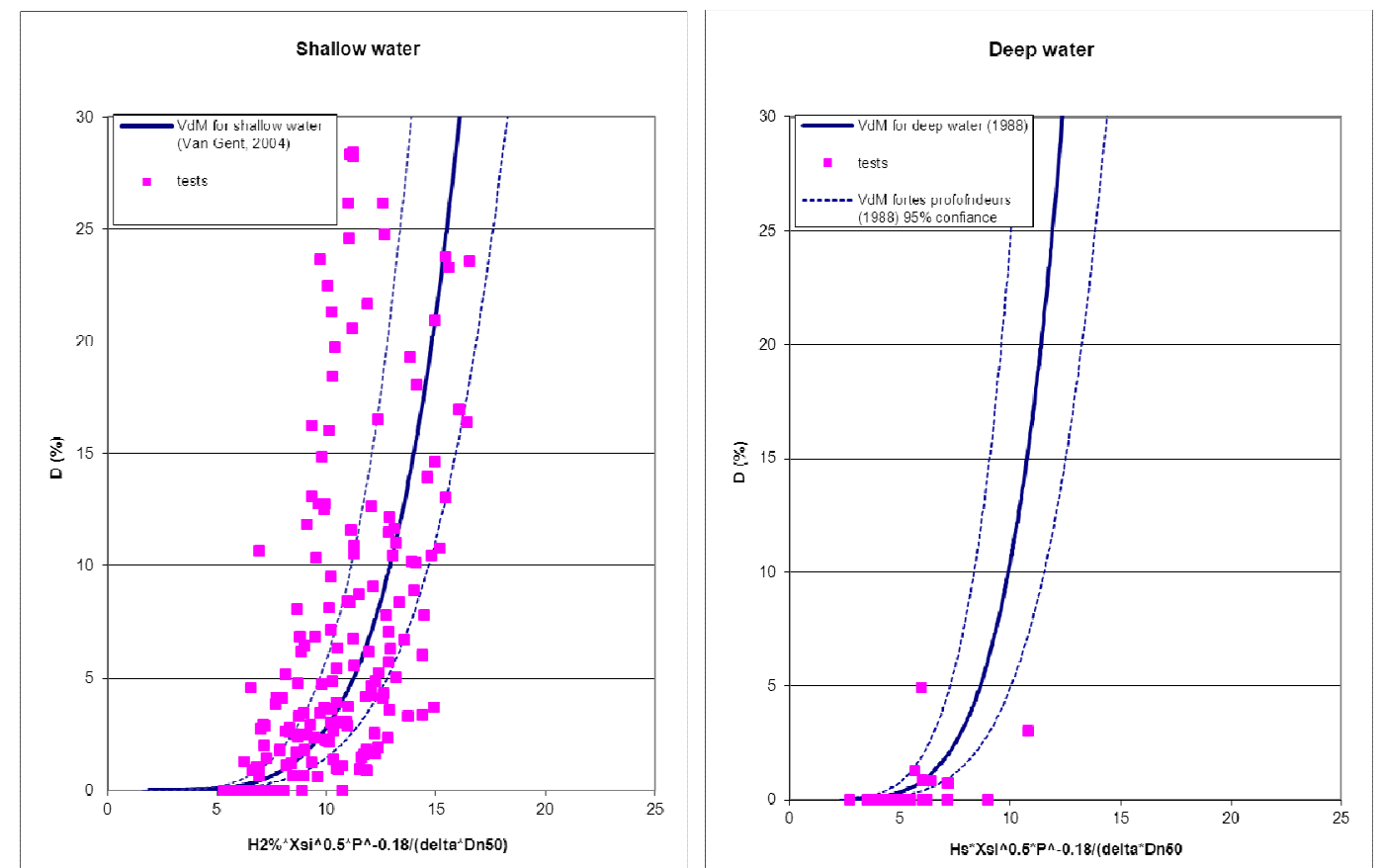

Figure 8 : Tests Represented as a Function of Shallow Water Criteria (3 Hs toe $>$ Dp ) with the Curves of the Van der Meer Formulas for Shallow and Deep Water.

Clearly, the shallow water criterion is insufficient. However, by replacing the factor of 3 with a factor of 1.75 , the result highlights two developments in a way that is consistent with the theoretical formulas (figure 10).
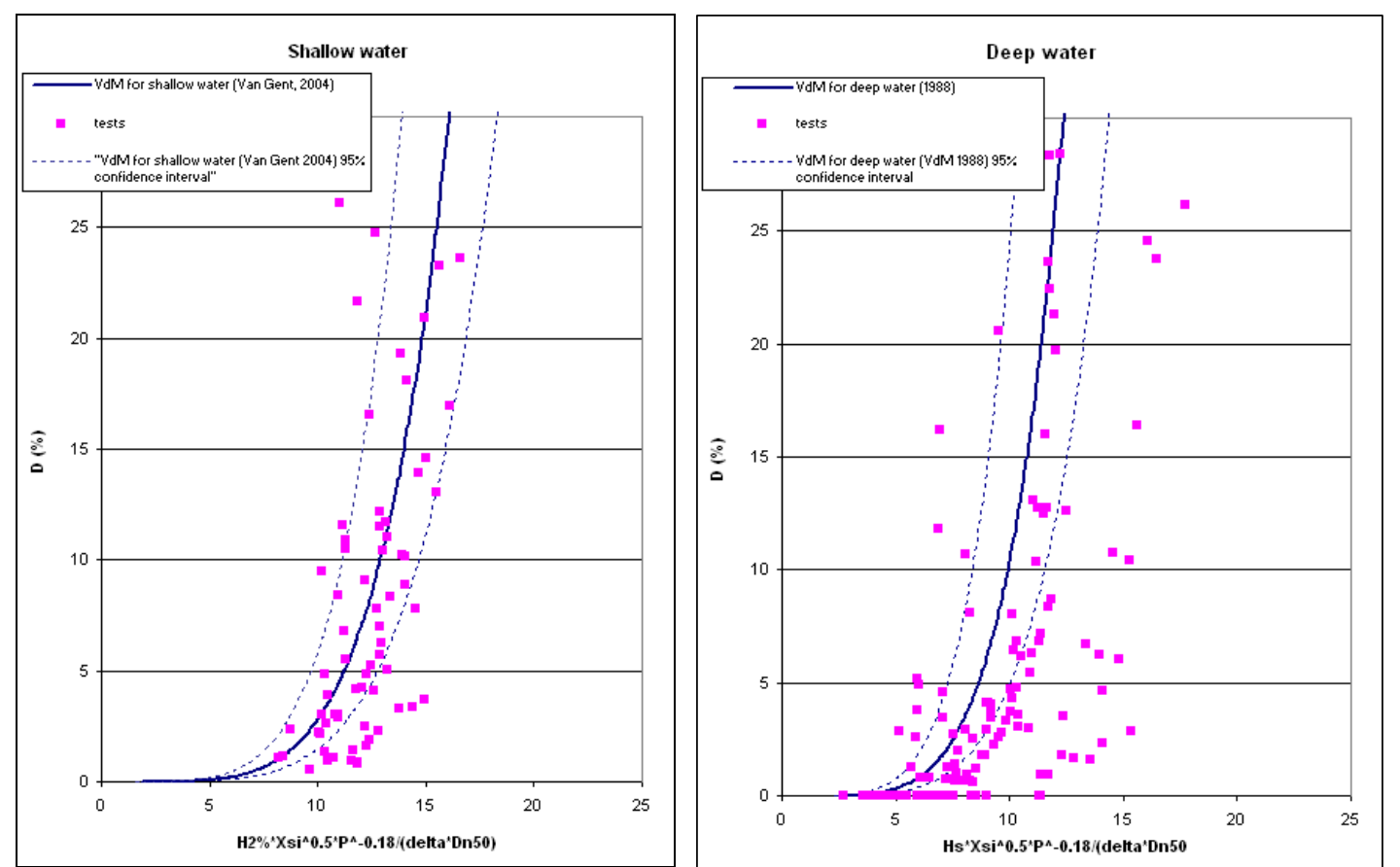

Figure 10: Tests Represented as a Function of Shallow Water Criteria $\left(1,75 \mathrm{H}_{\mathrm{s}}\right.$ toe $\left.>\mathrm{Dp}\right)$ with the Curves of the Van der Meer Formulas for Shallow and Deep Water.

Moreover, a relation can be made between the Figure 6 and 10 and the two criteria. For $\mathrm{R}<2$, the wave amplitude is limited which is consistent with the application domain proposed above: $\mathrm{R}<1,75$ for the shallow water Van der Meer equation. 


\section{CONCLUSION}

Conditions for waves in shallow water have been studied and simulated. They recreate several typical behaviours of waves approaching a structure and/or the shore: shoaling (or the increase of wave amplitude) and wave breaking. The tests conducted in Canal 12 of LNHE permitted the consideration of a wide range of such conditions. Approximately 250 tests were conducted for three water levels, three periods, and many wave amplitudes. During these tests, damage of a simplified rubble mound breakwater model was determined and the type of wave break before the structure was observed.

The test results were compared to the predicted damages by the existing formulas and methods of predesigning for shallow water conditions. According to the tests, the better pre-sizing method is that of Van der Meer modified by Van Gent (2004) for shallow water. Further, following the tests, the separation criteria between deep and shallow water $\left(3 H_{s}\right.$ toe $\left.>D_{p}\right)$ was modified by proposing a factor of 1,75 instead of a factor of 3 . The new shallow water criteria proposed is therefore $1,75 H_{s}$ toe $>D_{p}$,

This study is the subject of a report that lists all the characteristics of the tests, the methods employed and interpretations. In the context of shallow water (large $H_{s}$ toe $/ D_{p}$ ), the toe of the structure is subjected to high stress. Although formulas exist, our tests have shown their limitations (the structure was eventually constructed using a trench and a wooden plank in order to overcome toe stability problems). In the future, an experimental study of this vital breakwater component could provide interesting results.

\section{REFERENCES}

Feuillet J, Coeffe Y, Bernier J, Chaloin B, Le dimensionnement des digues à talus. France : Éditions Eyrolles, «Collection de la direction des études et recherches d'électricité de France »,Vol. 64, 1987. 172 pages.

Ciria, Cur, Cetmef, Guide Enrochement. L'utilisation des enrochements pour les ouvrages hydrauliques. French version of the Rock Manual. CETMEF, Compiègne, 2009, 1303 pages

Goda Y, Random Seas of Maritime Structures. Japon, Coll. «University of Tokyo Press », 1985. 323 pages.

Van der Meer J, Rock Slopes and Gravel Beach under Wave Attack, thèse, Grafischeverzoging Waterlookpkundig Laboratorium, 1988, 162 pages

Van Gent M.J, Smale A, Kuiper C, Stability of rock slopes with shallow foreshores. Proc. $4^{\text {th }}$ international coastal structure conference, Portland, ASCE, Reston, 2003

Hughes A.S, Physical models and laboratary techniques in coastal engineering. Singapour : World Scientific, coll. «Advanced Series on Ocean Enginnering », Vol.67, 1993. 568 pages.

CERC, Shore protection manual (SPM) $4^{\text {th }}$ edition, Coastal Engineering Research Center, Vicksburg, 1984 